\title{
Efectos del uso de la fuerza pública durante la pandemia de la COVID-19
}

\author{
Effects of the Use of Public Force during the COVID-19 Pandemic \\ Uladislao Zevallos Acosta ${ }^{1, a}$ \\ https://orcid.org/O000-0003- 36473224
}

Recibido: 07-04-2020

Arbitrado por pares

Aceptado: 01-06-2020

\section{Citar como}

Zevallos, U. (2020). Efectos del uso de la fuerza pública durante la pandemia de la COVID-19. Desafíos, 11(1); 70-83. https://doi. org/10.37711/desafios.2020.11.1.143

\section{RESUMEN}

Este texto busca llustrar la forma cómo el Estado cumple el rol del poderío de la fuerza pública para lograr el cumplimiento del supuesto o hipótesis de la norma jurídica de manera obligatoria y general frente a la sociedad en riesgo y los delitos en el Perú. Existen motivos justificables para el empleo del uso de la fuerza pública, cumpliéndose a través de instituciones tutelares como la Policía Nacional del Perú (PNP) y las Fuerzas Armadas (FF.AA.); entidades capacitadas para asegurar la prevención y guardar el orden público, así como la seguridad y soberanía nacional. El propósito de esta publicación es, por tanto, difundir los efectos y el significado de la fuerza pública del Estado, así como el cumplimiento coactivo de la norma jurídica frente al rebelde en circunstancias del coronavirus; pandemia mundial que azota a la nación peruana, con consecuencias impredecibles. Entonces cabría estar al corriente ¿para qué sirve el uso de la fuerza pública lícita y cuáles son las huellas de la COVID-19 en salubridad, economía, trabajo y educación? Partiendo de que el uso de la fuerza del Estado comprende la actividad policial y militar para hacer cumplir las disposiciones jurídicas del gobierno en el logro de la prevención, tratamiento y seguridad de la población en sanidad e higiene de la población infectada, así como la sujeción del otro sector humano desobediente al mandato del poder establecido.

Palabras clave: uso de la fuerza pública, policial, militar, coacción, seguridad ciudadana y sanitaria.

\section{ABSTRACT}

Objective. To illustrate how the Government uses public forces to achieve compliance of the legal norm in a mandatory and general form to protect people at risk, and combat crimes in Peru. There are justifiable reasons for the use of the public force. This is achieved through tutelary institutions such as National Police of Peru (PNP) and Armed Forces (FF.AA). Entities capable of ensuring prevention and safeguarding public order, as well as national security and sovereignty. Therefore, the purpose of this publication is to disseminate effects and meaning of the Government's public force. Coercive compliance with the legal norm against people who do not follow those mandatory norms during the coronavirus pandemic. A pandemic with unpredictable consequences. In this sense, it would be necessary to be up to date about the use of lawful public force. What are the consequences of COVID-19 in health, economy, work, and education? The use of force by the Government includes: police and/or military activity to enforce legal provisions for prevention, treatment and safety of the population. This includes health and hygiene of the infected population, and restraint of people disobedient to the mandate of the established power. Keywords: use of public force, police, military, coercion, citizen and health security.

\section{Filiación y grado académico}

${ }^{1}$ Universidad de Huánuco. Huánuco, Perú.

a Doctor en derecho. 


\section{INTRODUCCIÓN}

Para establecer los límites del empleo de la fuerza del Estado, ubicamos por ejemplo como antecedente remoto el desarrollo del gobierno (2006-2011), el cual dejó un saldo macroeconómico positivo que los expertos coinciden en destacar. Sin embargo, existió también otro más oscuro con 191 personas muertas durante los conflictos sociales, según el jefe de la Oficina de Gestión de Conflictos Sociales de la Presidencia del Consejo de Ministros. En este sentido, Caballero (2020) menciona que cabría preguntarse entonces: ¿cuáles son las reglas para el uso de la fuerza del Estado en los casos de resistencia, agresividad o rebeldía de los ciudadanos intervenidos?

La prevención de los conflictos sociales y el tratamiento de los mismos fueron mínimos y, más bien, la privación de la libertad o detención fue la coacción de uso; conllevando a la brusquedad, violencia y convulsión en zonas como Puno donde, a pocos días de la segunda vuelta electoral (2011), las protestas pusieron en peligro la realización del sufragio electoral.

Otro dato que llama la atención sobre el manejo de conflictos sociales y la fatal consecuencia de este es la clara tendencia al alza entre el 2006 y 2011 con un saldo creciente de personas muertas ocasionadas durante este contexto de desorden social.

Las fuerzas del orden resguardan el cumplimiento del estado de emergencia sanitaria. (Foto: GEC) y el desborde social. Fuente: Grupo El Comercio, 2020.

En el registro de la Defensoría del Pueblo, por ejemplo, se contabilizaron 214 bajas en el año 2011. Ahora bien, en concepto del Instituto de Defensa Leal

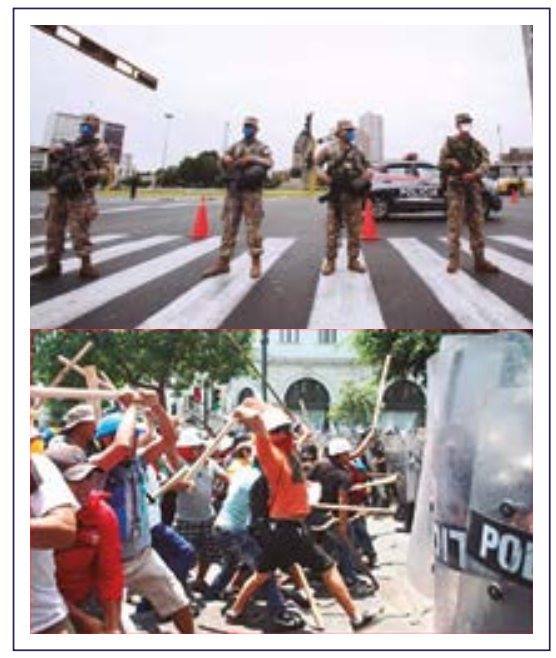

Fuente: Grupo El Comercio, 2020. Las fuerzas del orden resguardan el cumplimiento del estado de emergencia sanitaria. (Foto: GEC) y el desborde social.
Tabla 1

Conflictos Sociales fatales con uso de la fuerza pública

\begin{tabular}{lc}
\hline Años & $\begin{array}{c}\text { Fallecidos } \\
\text { Conflictos sociales fatales } \\
\text { con uso de la fuerza pública }\end{array}$ \\
\hline 2006 & 17 \\
2007 & 28 \\
2008 & 35 \\
2009 & 66 \\
2010 & 35 \\
2011 primer trimestre & 10 \\
Sub total: seis años & 191 \\
\hline
\end{tabular}

Nota. Luque (2014) Defensoría del Pueblo.

(IDL), el uso de la fuerza policial en protestas sociales es imprescindible para suministrar seguridad a los ciudadanos, jueces, fiscales, demás autoridades y a los propios policías quienes controlan el ejercicio de la violencia legítima: "Prevé mecanismos previos al uso de esta fuerza (presencia policial, verbalización, control de contacto, control físico y tácticas defensivas no letales), establece los principios básicos (legalidad, necesidad y proporcionalidad) y les da fuerza interpretativa a normas internacionales importantes". Luego, en el actual escenario de declaratoria del estado de emergencia nacional por salud y aislamiento social obligatorio, presentamos por muestreo bajas humanas por contagio e infección del Virus SARS-CoV-2, que superan ampliamente los fallecimientos en comparación al cuadro anterior (Luque, 2014).

Esta garantía de control social para evitar la propagación del coronavirus en el Perú, conllevó al gobierno a impartir normas jurídicas coactivas para neutralizar la pandemia; pero, al existir resistencia en muchos pobladores, incorporó el uso de la fuerza pública a partir del mes de febrero del 2020 en todo el país.

\section{MÉTODOS}

Se operacionalizó con el método descriptivo, hermenéutico, con ejercicio de análisis explicativo, bibliográficoy documental, respecto a los problemas que vive la sociedad, el Poder Judicial, las fuerzas del orden (policial y militar); tratando que el abogado defensor sea previsor, crítico, contestatario, humanista y pueda afrontar y participar en los problemas que vive la ciudadanía en las diversas protestas públicas. Además, se busca contribuir al cuestionamiento y la difusión de programas para purgar la corrupción casi generalizada y, en el caso específico en el devenir del COVID-19, a observar el empleo de la fuerza pública bajo régimen de emergencia, en el que fueron suspendidos ciertos derechos fundamentales; del que inferimos: 
Tabla 2

Propagación del Virus SARS-CoV-2 en el Perú

\begin{tabular}{|c|c|c|c|c|c|c|}
\hline \multirow{3}{*}{ no Día } & \multirow{3}{*}{ Fechas } & \multirow{3}{*}{ Diarios } & \multicolumn{4}{|c|}{ Evolución de la propagación del virus SARS-CoV-2 en el Perú (15 Mar - 29 May) } \\
\hline & & & \multicolumn{3}{|c|}{ Perú del 15 Mar al 29 May 2020} & \multirow[b]{2}{*}{ Datos mundiales (BBC) } \\
\hline & & & $\begin{array}{l}\text { Infectados o contagiados } \\
\text { (COVID-19) }\end{array}$ & Recuperados (+) & Fallecidos & \\
\hline 39 & $23 \mathrm{Abr}$ & Perú 21 & 20914 & 2786 & 571 & 183803 \\
\hline 43 & $28 \mathrm{Abr}$ & La República & 28699 & 8425 & 782 & 212486 \\
\hline 49 & 04 May & La República & 47372 & 12427 & 1344 & 249092 \\
\hline 51 & 06 May & La República & 54817 & 17527 & 1533 & 259710 \\
\hline 52 & 07 May & La República & 58526 & 18338 & 1627 & 263862 \\
\hline 56 & 11 May & La República & 67307 & 22406 & 1961 & 284005 \\
\hline 57 & 12 May & La República & 72059 & 23324 & 2057 & 286534 \\
\hline 59 & 14 May & La República & 80604 & 25151 & 2267 & 297395 \\
\hline 63 & 18 May & La República & 94933 & 30306 & 2789 & 315850 \\
\hline 64 & 19 May & La República & 99483 & 36524 & 2914 & 319651 \\
\hline 66 & 21 May & La República & 108769 & 43587 & 3148 & 329142 \\
\hline 67 & 22 May & La República & 111698 & 44848 & 3244 & 333733 \\
\hline 71 & 26 May & La República & 123979 & 50949 & 3788 & 348551 \\
\hline 73 & 28 May & La República & 141779 & 59442 & 4099 & 356703 \\
\hline 74 & 29 May & La República & 148285 & 62791 & 4230 & 361484 \\
\hline 74 & 30 May & La República & -- & -- & 140 policías & -- \\
\hline
\end{tabular}

Fuente: prensa nacional, Ministerio de Salud, \#YoMeQuedoEnCasa; adaptada por el autor.

\section{¿El uso de la fuerza implicaría el abuso del derecho?}

Durante esta época de agitación, turbulencia y pruebas (COVID-19), el abuso del derecho concurre cuando una persona, usando algún tipo de derecho, causa perjuicio ( $p$. ej., derecho a la propiedad o derecho crediticio), realiza un acto del que resulta daño para un tercero y ninguna utilidad para él (Torré, 2003). Cuando estamos frente a un uso abusivo, injusto y antisocial de un derecho, del que surge la obligación de reparar el daño ocasionando (por eso es fuente de obligaciones).

En cambio, es evidente que el abuso del derecho se parece mucho a los actos ilícitos (p. ej., delito de usurpación o atentado a los bienes jurídicos en general, como contra la vida, el cuerpo o la salud, violencia y resistencia a la autoridad, y violencia contra funcionario público) (Art. $367^{\circ}$, inc. 3) del Código Penal etc. Y en el que, por tanto, es ejercido sin derecho.

Se entiende que el abuso del derecho comentado por Rosas (2015) es el ejercicio de un derecho excediendo los límites fijados por la buena fe o, cuando se violan o exceden, el fin de la norma en vista del cual ese derecho se ha conferido.

Dos son principalmente, las concepciones que se han expuesto para caracterizar el ejercicio abusivo del derecho. Una de ellas da lugar a los sistemas que podemos denominar 'subjetivos' que consideran que el acto es abusivo cuando existe un obrar doloso o culposo del sujeto; la otra, de tipo 'objetivo', atiende a los fines de la norma jurídica y estima que el acto es abusivo cuando se violan o exceden esos fines (p. 3).

El Tribunal Constitucional (TC) considera al abuso del derecho como la aplicación fraudulenta de la Constitución; todo ello, en abierta contravención de los dispositivos, principios y valores materiales de la Constitución.

Así, cuando no se salvaguarda la libertad corpórea, seguridad personal, integridad física, psíquica y moral, además de los otros derechos conexos. Cuando no se protege a la persona contra cualquier autoridad que, ejerciendo funciones jurisdiccionales (en este particular argumento, se aplicaría como remedio procesal el habeas corpus), que adopta resoluciones violando la tutela procesal efectiva y, consecuentemente, lesiona la libertad individual.

Sobre esta figura, el Art. $103^{\circ}$ de la Constitución Política del Estado (1993), señala que no ampara el abuso del derecho. Cuyo Artículo fue sustituido por Ley n. ${ }^{\circ} 28389$, publicada el 17 de noviembre de 2004.

Antes de la reforma, este artículo tuvo el siguiente texto:

Art. $103^{\circ}$. - Pueden expedirse leyes especiales porque así lo exige la naturaleza de las cosas, pero no por razón de la diferencia de personas. 
Ninguna ley tiene fuerza ni efecto retroactivos, salvo en materia penal, cuando favorece al reo. La ley se deroga sólo por otra ley. También queda sin efecto por sentencia del TC que declara su inconstitucionalidad. La Constitución no ampara el abuso del derecho (p. 34).

La teoría del abuso del derecho, según Cuentas (1997), surge como una figura jurídica resultante de la evolución del derecho que refleja la evolución de la vida social, donde surgen nuevas instituciones, nuevas relaciones sociales y, por ende, nuevas relaciones jurídicas, nuevas concepciones del derecho. Al respecto, el mismo autor agrega:

Los tratadistas de derecho están de acuerdo en que la vida en sociedad impone la represión de la mala fe, del egoísmo y de actos, aun triviales, que origine una persona en el ejercicio de sus derechos, en detrimento de terceros. Asimismo, lo están en la necesidad de que el derecho positivo debe acoger esa represión mediante una fórmula que solucione satisfactoriamente el conflicto de intereses entre el agente que ejerce su derecho en forma abusiva y el tercero que queda afectado por ese ejercicio. Como dice Raymundo Saleilles surge la necesidad de un correctivo indispensable para conciliar los derechos del individuo con los de la sociedad (p.464).

A tal razón, según el apotegma romano: "No hay culpa, si no se han hecho todas las diligencias que habrían realizado los más diligentes". La teoría de la interpretación está destinada a desentrañar el significado y el qué quiere decir la norma jurídica, teniendo en cuenta la pirámide jerarquizada del sistema jurídico vigente, empleando el método y la integración jurídica para regular la producción del grado inferior como las reglas del uso de la fuerza policial y militar que "convergen en el Estado". Pero éste los devuelve al ciudadano transformando en garantías, que, en interpretación de Kant (1883), los atribuye con validez a priori a un principio que no es formal: la persona que, según él, constituye un fin en símismo. Un fin tal que, en su lugar, no podría ponerse ningún otro fin (como conclusión o resultado).

Plasmadas también en las garantías de un Estado fuerte, capaz de llevar a la práctica las políticas públicas, para dar sostenibilidad a la gobernabilidad y garantizar la plenitud del Estado democrático de derecho. Las políticas públicas se caracterizan como:

Una expresión de racionalidad política: tener una política en algún sector de actividad equivale a tener razones o argumentos racionales que permitan comprender tanto un problema como una solución. Una política pública es un marco de

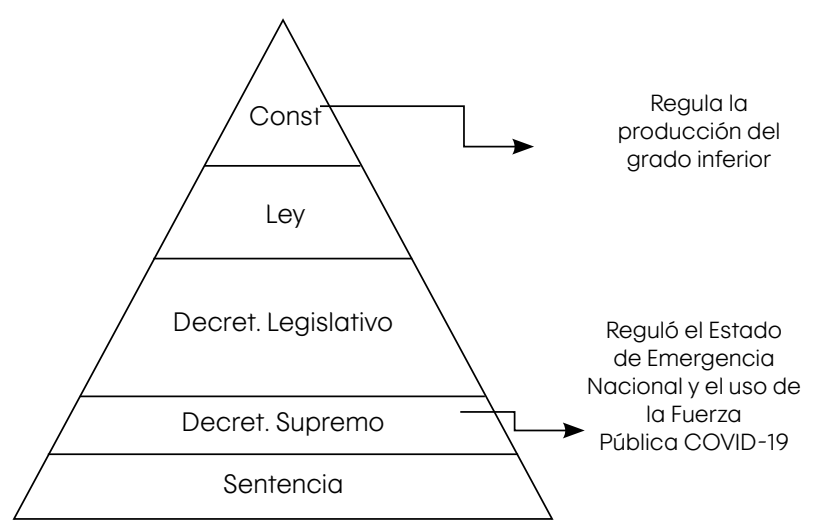

Nota: Autoría propia

Figura 1. Jerarquización de la norma jurídica.

orientación para la acción gubernamental en un sector de la sociedad o en un espacio geográfico. Las políticas públicas son conjuntos de objetivos, decisiones y acciones que lleva a cabo un gobierno para solucionar los problemas que en un momento dado los ciudadanos y el propio gobierno consideran prioritarios (Castro, 2014).

Como la increíble presencia del coronavirus en el Perú, que necesitaba una respuesta inmediata buscando la salubridad de manera obligatoria y coactiva. Concordante, asimismo, con la opinión de Delgado (2009) que manifestó:

Los policías saben que ante personas malcriadas, prepotentes, borrachas, solo queda usar la fuerza. No hay otra alternativa, porque si no se enmarroca a un borracho o no se detiene, este puede ocasionar una muerte (Delgado, 2009).

Para el mejor entendimiento del uso de la fuerza, recurriremos al método de la integración jurídica, que se produce cuando no hay norma jurídica aplicable y se debe, o se considera que se debe, producir una respuesta jurídica al caso planteado. Lo particular de la integración jurídica es que produce normatividad, pero no mediante las fuentes formales del derecho, sino mediante la aplicación del derecho mismo; como en este caso a través del D. Leg. n. ${ }^{0} 1186$ (2012) sobre el uso de la fuerza policial

Además, su utilización es restrictiva y no extensiva, debido precisamente a que constituye una excepción al principio predominante en el sistema romano-germánico-peruano, en el sentido de que las normas las da principalmente el organismo que tiene atribución normativa el Congreso de la República. Pero en el presente caso se produjo la delegación de funciones para que el Poder Ejecutivo legisle a través del citado Decreto Legislativo. 
Para comprender mejor esta realidad, acudimos al filósofo Radbruch (2005), quién señala que, "entre el mundo de la naturaleza, y el mundo de los valores, se halla el reino de la cultura en la que se ocupa el derecho" (p.53); y asevera que el concepto de derecho, es un concepto cultural, o lo que es lo mismo el concepto de una realidad, referida a valores, una realidad cuyo sentido consiste en estar al servicio de valores jurídicos. El derecho es la realidad que tiene el sentido de servir al valor jurídico, a la idea del derecho.

Según Bautista (2012), para servir al valor jurídico de la vida, se establece la excepcionalidad del uso de la fuerza letal. Para ese ejercicio tienen los policías derechos de desacatar una orden superior ilegal de uso de la fuerza (ya no rige la frase: la orden se cumple sin duda ni murmuraciones; sino el raciocinio lógico-jurídico de la responsabilidad y el rol del deber ser). También, tiene el policía derecho a recibir aprendizaje de técnicas para evitar que escale o remonte la violencia con entrenamiento adecuado según planes de capacitación bajo la supervisión del órgano especializado en derechos fundamentales con numerus apertus que el Ministerio del Interior debe suministrar, entrenándolos o ejercitándoles a disparar el tiro, proporcionándoles suficientes armas no letales y teniendo en cuenta que los ciudadanos no son sus subalternos, sino el fin supremo del Estado y de la sociedad, etc

El personal policial en el ejercicio de sus funciones, observará y se sujetará a los principios del Código de Conducta para funcionarios encargados de hacer cumplir la ley (art $10 .^{\circ}$ de la Ley Orgánica de la PNP): cumplir en todo momento los deberes que impone la ley, servir a la comunidad y proteger a las personas contra actos ilegales. Usar la fuerza sólo en caso estrictamente necesario (principio de necesidad y proporcionalidad en el uso de la fuerza)

La teoría del derecho ha desarrollado los conceptos de fuerza del Estado para el caso de su eventual incumplimiento de las personas; por eso se dice que tiene carácter coactivo. Para el caso de la coacción pongamos como por ejemplo el embargo de los bienes del deudor moroso que llega al remate judicial de sus bienes o el desalojo del precario. Alli existe el carácter coactivo, fuerza coactiva o fuerza del Estado. Es un hecho objetivo (o como la medida de coerción procesal penal establecida en el art. 253.3 del Código Procesal Penal/2004 in fine, relacionado con la restricción del derecho fundamental que solo tendrá lugar cuando fuera indispensable en la averiguación de la verdad o para evitar la reiteración delictiva).
Los medios de coerción en el proceso penal, según Oré (2014), son conceptuados de acuerdo a la siguiente precisión:

Que son limitaciones o restricciones al ejercicio de los derechos de la libertad personal, integridad personal, propiedad, a la inviolabilidad del domicilio y al secreto de las comunicaciones y otros de naturaleza constitucional que el estado impone al imputado o a terceros durante el transcurso de un proceso penal y bajo los términos establecidos por ley, con la finalidad de evitar la frustración de la averiguación de la verdad, garantizar la aplicación de la ley penal y el debido cumplimiento de la reparación civil (p. 20)

Asimismo, agrega que, para garantizar el resultado del proceso, en doctrina dicho instrumento (fuerza del Estado) adopta diversas denominaciones, tales como: medidas de coerción o actividad coercitiva, medidas cautelares, medidas precautorias, peticiones precautorias, proceso cautelar, medidas provisionales, actuaciones de aseguramiento, entre otras.

Los medios de coerción en materia de seguridad ciudadana, lucha contra la delincuencia y crimen organizado, vienen a ser el trabajo de prevención a través del patrullaje en sus diversas formas y estilos, empleando la fuerza de la persuasión y fuerza moral; pero, cuando no existen resultados esperados, recién se pasa al empleo de la fuerza policial.

El D. Leg. n. 1186 el marco legal que regula el uso de la fuerza por parte del personal de la PNP en cumplimiento de su finalidad constitucional (art. Segunda Disposición Complementaria Final) ha contemplado derechos de los policías, quienes deberán recibir atención psicológica y acompañamiento, cuando maten a una persona.

Asimismo, establece la excepcionalidad del uso de la fuerza letal, prevé mecanismos previos al uso de esta fuerza (presencia policial, verbalización, control de contacto, control físico y tácticas defensivas no letales), establece los principios básicos (legalidad, necesidad y proporcionalidad) y les da fuerza interpretativa a normas internacionales importantes, para enfrentar las protestas sociales sin el empleo de armas letales; salvo en casos excepcionales como se pasa a explicar.

Uno de los puntos negativos es la regulación del uso de la fuerza policial en casos de conflictos sociales, en su art. 8.3; dicha norma indica que la fuerza letal se utilizará cuando haya un riesgo real e inminente de muerte o lesiones graves. Sin embargo, para conflictos sociales se exige que el riesgo sea 
real o inminente. Esto significa que en un proceso judicial ya no se debe demostrar que el riesgo de muerte fue real e inminente, sino solo uno de los dos adjetivos (real o inminente).

De otra parte, en el ordenamiento jurídico pretérito, se carecía de regulación del uso de la fuerza por parte del personal de la PNP; situación que llega a su término en el país, pues, el Ejecutivo en uso de sus facultades legislativas publicó el D. Leg. n. ${ }^{\circ} 1186$, publicado en el Diario Oficial El Peruano el 16 de agosto de 2012. Este, cuenta además con exposición de motivos, válido como fuente interpretativa de la norma, dentro del uso de las facultades legislativas del Poder Ejecutivo, quien regula el uso de la fuerza por parte de la PNP. Esta reglamentación se desarrolló además con el objeto de desarrollar y establecer los procedimientos, las reglas y las normas para la aplicación del uso de la fuerza a través del D.S. n. ${ }^{\circ}$ 012-2016-IN del 26 de julio de 2016 que, en su parte final, también determina:

El Ministerio del Interior, a través de la Policía Nacional del Perú, asigna armamento, vestuario, fornituras y equipos de protección al personal policial para resguardar su integridad física y garantizar el uso adecuado de la fuerza conforme a las disposiciones del Decreto Legislativo en comento; al respecto las Fuerzas del orden emplearán armas no letales como perdigones y balas de goma ante agresores que no cumplen la inamovilidad social obligatoria.

Por lo tanto, llena un vacío legal dado que anteriormente no se contaba con una normajurídica sobre el uso de la fuerza policial, sino con reglas de inferior jerarquía normativa; lo que permitía amplios márgenes de discrecionalidad. La Ley de Protección Policial, Ley n. 31012 del 28 de marzo de 2020 modificó el art. 20. ${ }^{\circ}$ numeral 11 del Código Penal, referido a la causa de eximente de responsabilidad penal del personal de las FF.AA. y PNP. El personal de las FF.AA. y PNP que, en el cumplimiento de su función constitucional y en uso de sus armas u otro medio de defensa, en forma reglamentaria cause lesiones o muerte.

A tenor de esto, también se modificó el Código Procesal Penal, incorporándose el artículo $292^{\circ}-A$, con el objeto otorgar protección legal al personal de la PNP para establecer que dichos efectivos solo podrán ser investigados bajo comparecencia con restricciones y no en prisión preventiva; quedando prohibido dictar mandato de detención preliminar judicial y prisión preventiva. La referida norma procesal brinda el servicio de asesoría y defensa legal gratuita al personal policial que afronta una investigación fiscal o un proceso penal o civil derivado del cumplimiento de la función policial, señaladas en el D. Leg n. ${ }^{\circ}$ 1267, Ley de la Policía Nacional del Perú y D. Leg. n. ${ }^{\circ} 1186$, que regula el uso de la fuerza por parte de la Policía Nacional del Perú; precisado que el policía que hace uso de sus armas o medios de defensa, contraviniendo la Constitución Política del Perú y las normas del Derecho Internacional Humanitario (DIH) reconocidas por el Estado peruano, incurrirá en responsabilidad penal y no se le aplicarán los beneficios de la norma adjetiva.

También mediante Ley $n .^{\circ} 31012$ se incorporó al art. $15^{\circ}$, inc. F, del D. Leg. n. ${ }^{\circ} 1068$ (El Peruano, 28 de junio de 2008) del Sistema de Defensa Jurídica del Estado, al: "f) Procurador Público Especializado en la defensa legal de la PNP, justamente para que coadyuve a la protección legal del personal de la misma.

Por otra parte, el D. Leg. n. 1095 que establece reglas del empleo y uso de la fuerza por parte de las FF.AA. en el territorio nacional y su Reglamento DS n. ${ }^{\circ}$ 003-2020-DE, que en su art. 30 establece reglas de empleo y uso de la fuerza por parte de las Fuerzas Armadas en el territorio nacional. En estricta concordancia con el literal d) del artículo $2^{\circ}$ de la Ley n. $^{\circ} 30336$, que delega en el poder ejecutivo la facultad de legislar en materia de seguridad ciudadana, fortalecer la lucha contra la delincuencia y el crimen organizado para potenciar la capacidad operativa de la PNP; lo que en el ámbito de la aplicación de su facultad de usar la fuerza supone dotarla de reglas jurídicas claras con estándares internacionales que permitan ejercer cabalmente la función policial para velar por la protección, seguridad y el libre ejercicio de los derechos fundamentales de las personas, el normal desarrollo de las actividades de la población y prestar apoyo a las demás instituciones del Estado, en el ámbito de sus competencias y funciones. Sobre esta situación el Tribunal Constitucional declaró parcialmente inconstitucional dicha ley sobre el uso de la fuerza militar en el expediente STC, Exp. n. ${ }^{\circ}$ 00002-2008-PI/TC, f. j. 46, teniendo en cuenta que las reglas del Derecho Internacional Humanitario (DIH) no se aplican a los disturbios internos. Por ello, se consideró evidente que un grupo de personas que tiene armas punzo cortantes o contundentes, no puede, objetivamente, equiparar ni superar las armas y el entrenamiento de la Policía y las FF.AA.

\section{Entonces la norma jurídica determina reglas:}

1. de orden general para el uso de la fuerza;

2. de esta manera señala que aquella debe usarse de manera progresiva y diferenciada;

3. vale decir, que la fuerza deberá graduarse de acuerdo a los medios y métodos a emplear teniendo en cuenta: el nivel de cooperación, resistencia o agresión que represente la persona a intervenir o la situación a controlar. 
Para controlar los conflictos sociales, o para solucionarlos cuando estallan desalojos de viviendas, desalojos en invasiones de tierras o desalojos de mercados, la PNP tiene que hacer uso de la fuerza coactiva del Estado; como en los numerosos casos ocurridos en la última década en el país, teniendo como ejemplos paradigmáticos, lo ocurrido:

- En el ex Mercado Mayorista de Santa Anita y el exitoso operativo de desalojo luego del ultimátum al haber llegado la hora del desalojo con intervención del Ministerio Público, Municipalidad de Lima y PNP. La planificación e intervención fueron impecables con resultado pacífico, protegiendo a niños, pese a que los invasores contaban con armas de fuego y explosivos durante el desalojo (Ventana Indiscreta 2007).

En el desalojo del Mercado Mayorista La Parada, ubicado en el distrito de La Victoria. Debido a la resistencia de los vendedores, la violencia se desbordó, dos personas fallecieron, al menos 108 resultaron heridas y tres policías fueron brutalmente golpeados por los enardecidos comerciantes informales (El Comercio, 2012)

- En el bloqueo de vías, puentes, aeropuertos (son interrumpidas por protestas sociales 500 kilómetros de vía terrestre a través de la cual se transporta la producción de las minas Constancia y Antapaccay (Cusco), Las Bambas (Apurimac) y Cerro Verde (Arequipa), que llega directamente a Matarani).

- En los iincidentes cruentos del "baguazo" amazónico (5 de junio del 2009) se registraron incidentes en Bagua (Amazonas), producto de un enfrentamiento entre Policías y nativos de Bagua. Los agentes de la Dirección Nacional de Operativos Especiales (DINOES), con apoyo de las FF.AA., recibieron la orden de despejar la carretera Fernando Belaunde Terry. En un inicio lanzaron bombas lacrimógenas y después usaron armas de fuego, agravando la situación. Los manifestantes tomaron rehenes entre los que se encontraba el mayor de la PNP, Felipe Bazán, de quien hasta ahora se desconoce su paradero. El enfrentamiento fue contra cientos de nativos que estaban atrincherados más de 50 días en la zona conocida como la Curva del diablo. Este conflicto social dejó un saldo de 33 personas muertas, incluidos 23 policías.

- En el proyecto minero Conga cajamarquino, paralizado desde el 29 de noviembre de 2011, con heridos y detenidos e innumerables protestas. La comunidad solicitó que el proyecto fuese declarado inviable.

- Otro caso, de violencia social ocurrió en la Estación 6 de Petroperú, en Imasita (Amazonas), el 6 de junio de 2009, cuando los indígenas tomaron como rehenes a 39 personas (38 policías y un ingeniero), a quienes golpearon con sus lanzas. Diez de ellos fueron asesinados, entre los que se encontraba el comandante de la PNP Miguel Montenegro.

En el paro indefinido en la región Arequipa, el 5 de agosto de 2019, en contra de la realización del proyecto minero Tía María, a cargo de Southern Perú. El puerto de Matarani pudo reiniciar el desembarco de productos con las medidas de protección dispuestas por el Gobierno con la intervención de las FF.AA.

El gobierno optó por "salvaguardar la salud pública” (mediante el D.S. n. ${ }^{\circ}$ 008-2020-SA), cuando declaró la emergencia sanitaria a nivel nacional por el plazo de noventa (90) días de calendario; se dictaron medidas de prevención y control de la COVID-19 y se dispuso que toda persona que ingrese al territorio nacional proveniente de países con antecedentes epidemiológicos y que se encuentren en la relación que elabore el Centro de Epidemiología, Prevención y Control de Enfermedades-CDC del Ministerio de Salud, tales como la República Italiana, el Reino de España, República Francesa y República Popular de China, debe sujetarse a un periodo de aislamiento domiciliario por catorce (14) días; obligando a la población nacional a un aislamiento social para permanecer en sus domicilios y evitar contaminarse, con inmovilización social obligatoria entre las 21:00 a 05:00 horas. Por su parte las Fuerzas del Orden (FFAA y PNP) debían verificar el cumplimiento, practicar las verificaciones, e intervenciones de las personas, de los bienes, vehículos, locales, establecimientos, para comprobar e impedir que se lleven a cabo actividades no permitidas, verificando el aforo en los establecimientos comerciales, a fin de evitar aglomeraciones y alteraciones; así como ejercer el control respecto de la limitación del ejercicio de la libertad de tránsito, de las personas, en los diversos medios de transporte vehicular privado y público, medios acuáticos, etc.

- En la Declaratoria del Estado de Emergencia Nacional por las graves circunstancias que afectan la vida de la Nación a consecuencia del brote COVID-19, al haberse extendido en más de 120 países del mundo de manera simultánea, con inmovilización social obligatoria (denominada cuarentena) entre el 15 de marzo y el 26 de abril en el Perú; dispuesto de obligatorio cumplimiento con apoyo de la fuerza pública según D.S. n. ${ }^{\circ}$ 044-2020-PCM del 15 de marzo del 2020 y prorrogado por con sendos decretos supremos hasta el 30 de junio de 2020.

- El D.S. n. ${ }^{\circ}$ 051-2020-PCM establece la inmovilización social obligatoria, solo para la adquisicióndeviveresoproductosfarmacéuticos, 
solo está permitido el desplazamiento de una persona por núcleo familiar. Los días lunes, miércoles y viernes únicamente podían transitar personas del sexo masculino y los martes, jueves y sábados las personas del sexo femenino. Asimismo, el día domingo, la inmovilización social obligatoria es para todos los ciudadanos en el territorio nacional durante todo el día. Para la aplicación y control de la presente disposición, quedó prohibido cualquier tipo de discriminación, excepto a aquellas personas que debían circular para el cobro de cualquiera de los beneficios pecuniarios otorgados por el Gobierno en el marco de la Emergencia Nacional, así como para el cobro de pensiones en las entidades bancarias. Siendo obligatorio el uso de mascarilla para circular por las vías de uso público. Lo que en resumen constituyeron acciones del uso de la fuerza pública del Estado, con el fin de salvaguardar la salud pública nacional y a quienes incumplían, los retenían, los registraban para su posterior proceso penal con intervención del Ministerio Público, por desacato a la autoridad. Quedando suspendidos los derechos constitucionales relativos a la libertad y seguridad personales y la inviolabilidad de domicilio, comprendidos en los incisos 9) y 24) apartado f) del artículo $2^{\circ}$ de la Constitución; y los militares y policías que cometan delito común, serán juzgados con el Código Penal y Código Procesal Penal en el fuero ordinario.

\section{¿qué son los coronavirus?:}

Los coronavirus son una gran familia de virus que causan enfermedades que van desde el resfriado común hasta enfermedades más graves como el sindrome respiratorio de Oriente Medio (MERS) o el síndrome respiratorio agudo severo (SRAS).
Pueden transmitirse entre animales y personas. Se propaga de persona a persona, a través de gotitas o partículas acuosas que se quedan en el ambiente al toser o estornudar. También podría contagiarse si se mantienes contacto físico con una persona infectada (Expreso, 18 de abril de 2020). Entre sus síntomas se encuentran los siguientes:

- Fiebre y escalofríos.

- Tos y estornudos.

- Dolor de garganta.

- Malestar general intenso.

- Respiración rápida.

- Sensación de falta de aire. Actualmente, no existe una vacuna para el coronavirus. A continuación, algunas medidas básicas y hábitos de higiene recomendadas por la OMS que deben tomarse en cuenta para evitar contagiarse:

- Lavarse las manos hasta el antebrazo con agua y jabón por un mínimo de 20 segundos.

- Al toser o estornudar, cubrirse la boca y nariz con un pañuelo desechable o con tu antebrazo; nunca hacer con las manos directamente.

- No tocarse los ojos, nariz o boca si no se ha lavado las manos primero.

- Solo si no se cuenta con agua y jabón cerca, utiliza gel antibacterial. Toma en cuenta que esto no debe reemplazar el lavado de manos.

- Evitar el contacto directo con personas que muestren síntomas como los del resfrío o gripe. Mantener un metro de distancia promedio.

- Cuando se usa papel higiénico o pañuelos descartables, asegurarse de botarlos en el basurero y lavarse las manos luego.

- Usar mascarillas quirúrgicas solo si debes atender a alguien bajo sospecha de infección, tiene tos o estornudos, o necesitas salir de casa por algún motivo permitido durante el aislamiento social obligatorio.

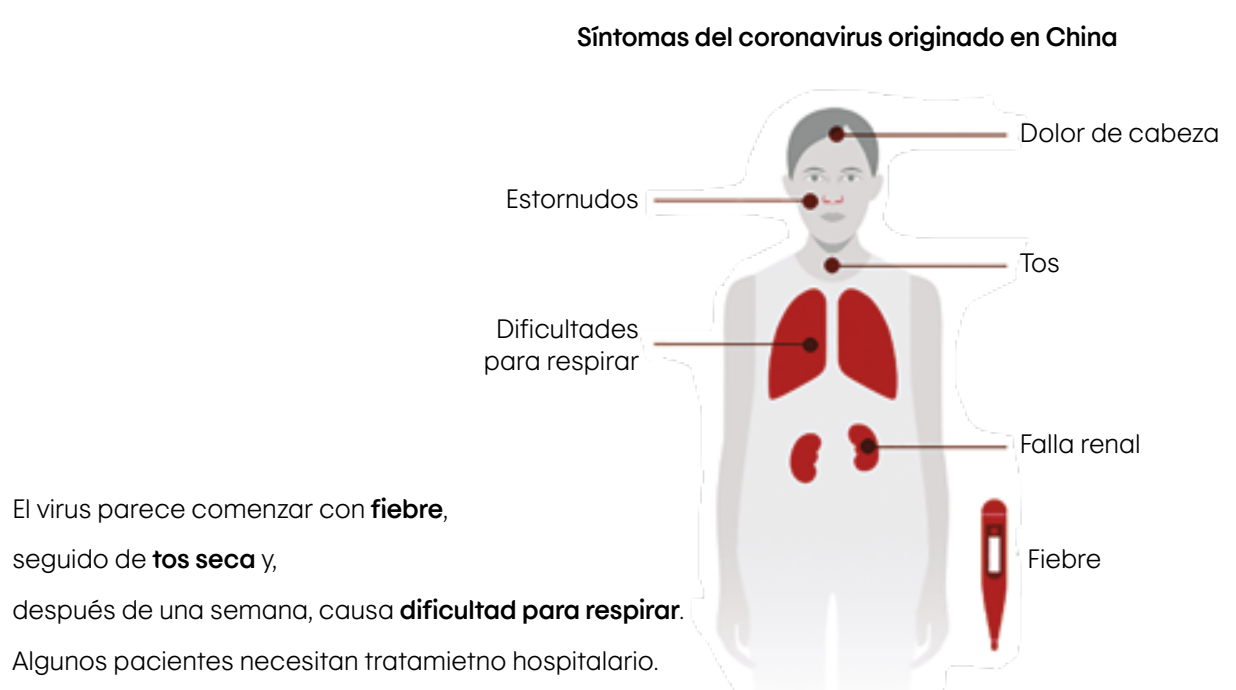

Figura 2. Sobre síntomas del coronavirus originado en China. 
Los pacientes contagiados con el coronavirus experimentan diversos síntomas; entre ellos, dificultad para respirar, fiebre, tos y dolor muscular. El período de incubación de la COVID-19 (es decir, cuánto tardan los síntomas en aparecer después de contraer la infección) es de entre 1 a 14 días.

El virus puede causar neumonía; es decir, inflamar los pulmones y llenar de agua los alveolos, los pequeños sacos donde el oxígeno pasa del aire a la sangre.

La técnica del lavado de las manos consiste:

- Al llegar a la casa u oficina.

- Luego de toser, estornudar o limpiarse la nariz.

- Antes de comer o manipular alimentos.

- Antes y después de usar una mascarilla.

\section{RESULTADOS}

El Coronavirus en el Perú repercute en la salud, la economía, el trabajo y la educación. Partiendo de que el uso de la fuerza del Estado comprende la actividad policial y militar, para hacer cumplir las disposiciones jurídicas del gobierno para el logro de la prevención, tratamiento y seguridad poblacional en salubridad e higiene de la población infectada y del otro sector humano desobediente al mandato del poder constituido; en consecuencia:

1. La finalidad del uso de la fuerza pública conlleva a que:

- El personal de la PNP en el ejercicio de sus funciones, observará y se sujetará a los principios del Código de Conducta (art. 10. ${ }^{\circ}$ de la Ley Orgánica de la PNP), referido también para funcionarios encargados de hacer cumplir la ley.

- Cumplan en todo momento los deberes que impone la ley, servir a la comunidad y proteger a las personas contra actos ilegales.

- Usar la fuerza sólo en caso estrictamente necesario (principio de necesidad y proporcionalidad en el empleo de la fuerza).

2. El Estado, para servir al valor jurídico de la vida, establece la excepcionalidad del uso de la fuerza letal; para ese ejercicio tienen los policías derechos de desacatar una orden superior ilegal de uso de la fuerza.

3. Los magistrados, procuradores, abogados defensores,agentes delorden(policíasymilitares), estudiantes de derecho se comprometen a ser previsores, críticos contestatarios y humanistas que pueden afrontar y ser partícipes en los problemas que vive la ciudadanía en las diversas protestas públicas, cuestionando verbalizando y difundiendo programas para purgar desacatos en el marco del COVID-19 generalizado.
4. Ahora, en concepto del Instituto de Defensa Leal (IDL), el uso de la fuerza policial en protestas sociales es imprescindible para darle seguridad a los propios policías, ciudadanos, además de jueces y fiscales, quienes controlarán el ejercicio de la violencia legítima.

5. La COVID-19 es la enfermedad infecciosa que fue descubierta en Wuhan (China) en diciembre de 2019, a raíz del brote del virus que empezó a acabar con la vida de gran cantidad de personas. El Comité Internacional de Taxonomía de Virus designó el nombre de este nuevo coronavirus como SARS-CoV-2.

6. Los efectos de la COVID-19 en Perú, generalizado al 29 de mayo de 2020, arrojan las consecuencia o resultados siguientes:

a) Deshonestidad y falta de transparencia: La corrupción encabeza la lista de las inquietudes nacionales para el $56 \%$ de peruanos (EI Comercio-Ipsos, 2020).

La crisis por la COVID-19 ocupa el segundo lugar. En plena guerra contra la COVID-19, ya se informa sobre la existencia de indicios razonables de corrupción que desarrollaba la alta cúpula del Ministerio del Interior en complicidad con los altos mandos de la Policía Nacional del Perú (Panamericana Televisión, 2020).

Evitar las acciones adversas de gobiernos locales, respecto a la corrupción vinculada con el mal manejo del presupuesto so pretexto de la adquisición de los artículos para evitar el contagio de la COVID-19 y las canastas de auxilio a la población de escasos recursos.

b) Economía: se transferirán 213 millones de Soles; siendo el valor de cada canasta familiar por repartir de S/. 80,00. En Latinoamérica cerca del $50 \%$ de los trabajadores está en el sector informal y, para ellos, la restricción de salir a la calle es económicamente devastadora. El coronavirus le viene costando al Perú, hasta ahora, S/ 109 mil millones, según reporta la BBC de Londres.

La región latinoamericana ha gastado cerca de un $2,4 \%$ del PIB, el mundo ha desembolsado un $3,7 \%$. El país que lidera la lista regional de mayor gasto fiscal frente a la pandemia es Perú (9 \% del PIB), mientras que en el otro extremo está Nicaragua con un nivel de gasto igual a cero. Sin embargo, se estableció el Bono Familiar Universal de 760 soles.

c) Educación: se desarrollan las clases virtuales en línea en todos los niveles educativos; asimismo, se implementó el uso de esta tecnología para las sesiones del parlamento.

d) Heridos: se reportan numerosos contusos y lesionados entre los servidores del serenazgo, la policía, Ios militares etc., como consecuencia de la resistencia de la población a acatar el 
estado de emergencia por salud y el uso de la fuerza pública.

Por ejemplo, un policía y un miembro del Ejército quedaron heridos tras ser golpeados por un grupo de personas que tomaban licor en la calle, en pleno toque de queda, en el distrito de Yucay, provincia de Urubamba, Cusco (tikitakas, 2020).

e) Fuerzas del orden:

Policías: al 30 de mayo 2020 van 140 policías fallecidos. El ministro del Interior, Gastón Rodríguez Limo, precisó que hay 3873 efectivos que están infectados por la COVID-19. Asimismo, informó que hay 360 hospitalizados y 17 en Unidad de Cuidados Intensivos.

FF.AA:: el titular del Ministerio de Defensa, Walter Martos, indicó que hay 349 contagiados con la COVID-19 en las tres instituciones que conforman las FF.AA. y cinco de ellos han fallecido por coronavirus (La República, 2020).

f) Instituto Nacional Penitenciario (INPE): estamos hablando de un universo donde hay prácticamente 100 mil internos e internas en el país. El jurista García Sayán recomienda identificar aquellos casos donde las penas están por vencer y articular una respuesta entre el sistema judicial y el Ejecutivo. Hay muchas internas que están embarazadas y otras que están detenidas por delitos menores de narcotráfico (las burriers y otras). Muchas de ellas extranjeras. En lugar de mantenerlas en la cárcel debieran ser deportadas y remitidas a sus países de origen. En tanto, el ministro de Justicia, Fernando Castañeda, anunció que la Comisión de Gracias Presidenciales del Ministerio de Justicia indultará a casi 3000 internos a nivel nacional para evitar que se contagien con la COVID-19.

7) El Colegio Médico del Perú: exhortó a la población a mantener la cuarentena a nivel nacional, por al menos, dos semanas más, para evitar un costo social mayor al que ya tenemos (La República, 2020) Entre los riesgos latentes, los cinco más preocupantes que podrían hacer colapsar el sistema de salud:

a. incremento de concentración de personas en los mercados, bancos y otros lugares de afluencia;

b. desplazamiento masivo de personas que retornan a sus regiones, muchos de los cuales lo hacen sin ningún control;

c. relajamiento de los controles sobre el cumplimiento de las medidas de aislamiento social:

d. rompimiento de la cuarentena por la búsqueda de apoyo alimentario en sectores desfavorecidos;

e. el desconfinamiento de la cuarentena como si se hubiera terminado la pandemia y como hubiéramos vuelto a la normalidad anterior al comienzo de esta crisis.

8) El equipo científico peruano: dirigido por el huanuqueño doctor Manolo Fernández y la Universidad Cayetano Heredia (UPCH), a través del proyecto "Producción de una vacuna anti SARS-CoV-2, basada en la proteína spike expresada en células de insecto, y la evaluación de su seguridad e inmunogenicidad en animales y humanos voluntarios", es financiado por el Fondo Nacional de Desarrollo Científico, Tecnológico y de Innovación Tecnológica-FONDECYT y se desarrolla en lca.

Prueban vacuna contra el COVID-19 en Alpacas. Se trata de Urpi, Chaska, Camila y Micaela; 4 alpacas del fenotipo Huacaya que han sido seleccionadas por PACOMARCA en la Estación Experimental de Investigación Científica y Mejora Genética de Alpacas perteneciente al Grupo Inca. A estos auquénidos se les inoculará una vacuna experimental con el objetivo de producir anticuerpos específicos contra el Coronavirus que servirán para las fases de prueba de una nueva vacuna y para la generación de anticuerpos en futuros tratamientos, cuyos resultados se proyectan para setiembre del presente año, según informó el Equipo Científico del Perú (Perú 21, 2020).

\section{Tabla 3}

Adaptada de la teoría de la taxonomía de habilidades de Bloom (1956)

\begin{tabular}{|c|c|c|}
\hline $\mathrm{n}^{\circ}$ & NIVEL & Conductas características del estudiante de Derecho, policial y militar \\
\hline 1 & Conocimiento & recordar, memorizar, reconocer, recuperar: información, dato \\
\hline 2 & Comprensión & interpretar, traducir de un medio a otro; describir con las palabras de uno mismo \\
\hline 3 & Aplicación & resolver problemas, aplicar información para producir algún resultado \\
\hline 4 & Análisis & $\begin{array}{l}\text { subdividir algo para mostrar cómo se reúnen sus partes, encontrar la estructura subyacente a una comuni- } \\
\text { cación o manejo, identificar motivos }\end{array}$ \\
\hline 5 & Sintesis & crear un producto único y original ya sea en forma verbal o como objeto físico \\
\hline 6 & Evaluación & $\begin{array}{l}\text { tomar decisiones de valor acerca de diferentes asuntos, resolver controversias o diferencias de opinión. } \\
\text { controlar para mejorar }\end{array}$ \\
\hline 7 & Investigación & investigación + desarrollo + innovación (i+d+i) \\
\hline
\end{tabular}


9) Organización Mundial de la Salud (OMS): dirigida por el doctor Tedros Adhanom Ghebreyesus. Es una agencia especializada de la ONU que tiene como objetivos "promover la salud, mantener el mundo seguro y servir a los vulnerables". Tiene oficinas en 150 países y alcance global. En casos de pandemias como la de la COVID-19, la OMS es la institución mundial de referencia que sirve para orientar y ayudar a coordinar las políticas sanitarias de la mayor parte de los estados.

La OMS decidió llamar a este virus COVID-19 tras los reportes de esta gripe neumónica:

$\mathrm{CO}=$ Corona

$\mathrm{VI}=$ Virus

$D=$ Disease (enfermedad en inglés)

19 = Por el año en el que fue registrado el primer caso de la enfermedad. El informe llegó a la OMS el 31 de diciembre de 2019.

Por otra parte, el presidente de Estados Unidos, Donald Trump, anunció que el país se retira de la Organización Mundial de la Salud en plena pandemia de la COVID-19 (La República, 2020). Además, anunció que romperán relaciones con la OMS, acusando una injerencia de Pekin, indicando que el gobierno chino ha violado continuamente la confianza de otros países. El mundo ahora está sufriendo las acciones del gobierno chino. China tiene todo el control sobre la OMS, a pesar de que solo pagan 40 millones de dólares al año, mientras que Estados Unidos aporta 450 millones de dólares al año.

Jack Chow, exembajador de Estados Unidos para la lucha global con el $\mathrm{VIH}$ y exsubdirector de la OMS sobre este rompimiento de relaciones, comentó ante la BBC Mundo: esto es como quitar el financiamiento al cuerpo de bomberos justo cuando enfrentas un incendio devastador.

En la entrevista al estadounidense, doctor Rashid Butta, este indicó que buscan despoblar a la población mundial, con fraude, con una conspiración con datos falsos, causando la pandemia, saltándose la ley, contra la moratoria del gobierno y está cambiando el planeta.

10) Médicos: 33 médicos héroes de la pandemia al 30 de mayo de 2020.

11) Salubridad, nacional: resultaron 4230 personas fallecidas en el Perú.

12) Salubridad mundial: resultaron 361484 personas fallecidas en diferentes países.

Muchas víctimas de la COVID-19 están muriendo en aislamiento hospitalario sin la compañía de familia ni amigos. Las visitas están prohibidas por el alto riesgo de contagio.

Enfermeros y tecnólogos médicos son también los otros héroes caídos en la guerra contra el coronavirus; son 16 peruanos que entregaron su vida a la salud pública y que fallecieron en la lucha contra la Covid-19. Desde sus profesiones, muchas veces invisibilizados, pelearon hasta el final dejando un legado de Idoneidad ( $L a$ República, 2020).

13) Trabajo: existe un enorme sector informal. La paralización de las actividades económicas por las cuarentenas tiene un impacto mucho más potente en los sectores que no pueden acogerse a los beneficios que tienen los empleados formales. Los trabajadores del sector público podrán realizar trabajo virtual o remoto desde sus respectivos domicilios, hasta fin de año y los trabajadores con licencia con goce de haber deberán compensar horas no laboradas incluso hasta en 2021. Se dispuso la figura jurídica laboral de la suspensión perfecta del trabajador. En el transcurso del día 30 de marzo de 2020 se habilitó la web http://www. gob.pe/paselaboral

14) Transporte: las ciudades contemplan impulsar el uso masivo de bicicletas frente a la crisis del COVID-19. Así, puede que nuestra forma de entender el transporte urbano cambie, evitando la contaminación ambiental e introduciendo la riqueza familiar. Esto supone una oportunidad para que el Perú adopte un cambio como en las décadas del 50 y 60 del siglo pasado de acuerdo al dicho: "la vida es como andar en bicicleta. Para mantener el equilibrio, debes seguir moviéndote". Hecho que reapareció como una alternativa factible para permitir un transporte más seguro frente a la pandemia del COVID-19 en distintas ciudades del mundo.

\section{DISCUSIÓN}

La normatividad sobre el uso de la fuerza pública (policial-militar), requiere de varios cambios en el trabajo pedagógico en el Centro de Formación Castrense, tomando la idea de Bloom (1956), en la taxonomía cognitiva; donde estas son clasificadas en seis niveles de complejidad creciente, sobre el pensamiento aprender y enseñar, entre ellos:

Tiene que desarrollar sus capacidades de prevenir problemas socio-jurídicos, no solo de solucionarlos. Debe poner énfasis en el aprendizaje de la sistemática del derecho y en sus principios de interpretación y aplicación (saber hacer los procedimientos en forma práctica o aplicada con creatividad).

Para ello, es decir, para el aprendizaje del derecho en centros de formación policial y militar, deben manejarse los tres primeros niveles (conocimiento, comprensión y aplicación) de la clasificación, así como la jerarquización de la 
teoría de la taxonomía de habilidades del mismo autor, sistematizada en el cuadro.

- La capacidad de evaluar (el nivel más alto de la taxonomía cognitiva), se basa en el supuesto de que el estudiante o servidor público policialmilitar tiene que disponer de la información necesaria, comprender esa información (servicio policial de inteligencia), para ser capaz de aplicarla, analizarla, sintetizarla y luego emplear la fuerza del Estado.

- La PNP puede detener sin mandato judicial (Art. 2o numeral 24 inc. f) de la Constitución -modificado por Ley n. 30558 del 9 de mayo de 2017 y art. 259 del Código Procesal Penal (CPP), a quienes sorprenda en flagrante delito; cuando el agente es descubierto en la realización del hecho punible, cuando el agente acaba de cometer el delito y es descubierto y además cuando ha huido y ha sido identificado, durante o inmediatamente después de la perpetración del acto antijurídico o cuando el agente es encontrado dentro de las 24 horas, después de la perpetración del hecho con efectos o instrumentos procedentes de aquel o que hubieren sido empleados para cometerlos o con señales en sí mismo o en su vestido que indiquen su probable autoría. El detenido será puesto a disposición de la autoridad competente dentro de las 48 horas o al término de la distancia.

- El Tribunal Constitucional ha precisado que la flagrancia delictiva, presenta dos presupuestos indispensables, en la comisión del delito: la inmediatez temporal; es decir, que el delito se esté cometiendo y que se haya cometido instantes antes, y la inmediatez personal; esto es, que el sujeto activo se encuentre alli en ese momento y situación y con relación al objeto o a los instrumentos del delito y que ello ofrezca una prueba evidente de su participación en el hecho punible.

- Mejorar drásticamente la seguridad ciudadana: con mejor coordinación entre los gobiernos nacional, regional, local y fusionando los sectores Interior y Defensa para luchar contra la inseguridad y como consecuencia del ejercicio real de la prevención del COVID-19 en el Perú.

- Según la interpretación de Immanuel Kant (1724-1804), filósofo alemán, en su obra Crítica de la razón pura (1983), la garantía que brinda el Estado los atribuye con validez a priori a un principio que no es formal.

- Tener una política en algún sector de actividad equivale a tener razones o argumentos racionales que permitan comprender tanto un problema como una solución. Una política pública es un marco de orientación para la acción gubernamental en un sector de la sociedad o en un espacio geográfico. Ellas son conjuntos de objetivos, decisiones y acciones que lleva a cabo un gobierno para solucionar los problemas que en un momento dado los ciudadanos y el propio gobierno consideran prioritarios, como el caso de la pandemia que actualmente azota.

- Para el mejor entendimiento del uso de la fuerza, se recurrió al empleo del método de la integración jurídica; este se produce cuando no hay norma jurídica aplicable y se debe, o se considera que se debe, producir una respuesta jurídica al caso planteado, produciendo normatividad, pero no mediante las fuentes formales del derecho, sino mediante la aplicación del derecho mismo, como en este caso a través del D. Leg. n. ${ }^{\circ} 1186$ sobre el uso de la fuerza policial y el D.S. n. ${ }^{\circ}$ 044-2020 que declaró el estado de emergencia nacional, por las graves circunstancias que afectan la vida a consecuencia del brote de la COVID-19.

- El uso de la fuerza empleada por los militares integrantes de las FF.AA. Ellos no podrán enfrentarse directamente a un grupo de ciudadanos que protestan, por ejemplo, premunidos de palos y piedras, sino que siempre lo harán prestando apoyo a la PNP en la función de mantener o restablecer el orden interno.

- El D. Leg. n. ${ }^{\circ} 1194$ (El Peruano 2015) se ha establecido que este es un proceso obligatorio inmediato para los casos de flagrancia; de modo que se ha modificado el artículo 446 del CPP y se ha dado una estructura completamente nueva a los artículos 447 y 448, que regulan los procesos sumarios; surgiendo como consecuencia el hacinamiento que hará colapsar las cárceles que ya están colapsadas, según alertó el jefe del Instituto Nacional Penitenciario (INPE), Julio Magán.

\section{Pudiendo arribar a las siguientes conclusiones:}

1. Los agentes castrenses conozcan y divulguen el significado del empleo de la fuerza pública del Estado, para neutralizar a las personas rebeldes, sin incurrir en el abuso del derecho o la realización de un acto del que resulten daños para terceros. Imponiéndose la represión de la mala fe.

2. La norma jurídica establece la excepcionalidad del uso de la fuerza letal. Los policías tienen el derecho de desacatar una orden superior ilegal de uso de la fuerza cuando se pretende atentar contra la vida del poblador. La gente debe evitar contagiarse por contacto cercano, y el personal médico y los custodios deben protegerse de la COVID-19.

3. Los agentes de la policía tienen derecho a ser 
capacitados en técnicas para evitar la escalada de la violencia a través del entrenamiento adecuado y, según planes de capacitación, bajo la supervisión del órgano especializado en derechos fundamentales con numerus apertus.

4. La policía debe asumir que los pobladores no son sus subalternos, sino el fin supremo del Estado y de la sociedad.

5. La teoría del derecho ha desarrollado el concepto de "fuerza del Estado" para el caso de su eventual incumplimiento de las personas; por eso se dice que tiene carácter coactivo y comprende los medios de la coacción y la coerción como herramientas objetiva y subjetiva, respectivamente.

6. Los medios de coacción en el proceso penal, son limitaciones o restricciones al ejercicio de los derechos de la libertad personal, a la integridad personal, a la propiedad, a la inviolabilidad del domicilio y al secreto de las comunicaciones; así como otros que el Estado impone al sujeto activo o imputado, o a terceros durante el transcurso de un proceso penal y bajo los términos establecidos por ley con carácter provisional, en tanto se emita la sentencia final.

7. Los medios de coerción en materia de seguridad ciudadana, lucha contra la delincuencia y crimen organizado, pero con el trabajo de prevención a través del patrullaje en sus diversas formas y estilos; empleando la fuerza de la persuasión y la fuerza moral, pero cuando no existen resultados esperados, recién se pasa al empleo de la fuerza policial efectiva.

8. El D. Leg. n. ${ }^{\circ} 1186$ en el marco legal que regula el uso de la fuerza por parte del personal de la PNP en cumplimiento de su finalidad constitucional, contempla derechos de los policías para recibir atención psicológica y acompañamiento, cuando maten a terceros, en cumplimiento del deber.

9. La función policial debe ajustarse a estándares internacionales para velar por la protección, seguridad y el libre ejercicio de los derechos fundamentales y prestar apoyo a las demás instituciones del Estado.

10. La fuerza letal se utilizará solo cuando haya un riesgo real e inminente de muerte o lesiones graves. Sin embargo, para conflictos sociales se exige que el riesgo sea real o inminente. Esto significa que en un proceso judicial ya no se debe demostrar que el riesgo de muerte fue real e inminente, sino solo uno de los dos adjetivos (real o inminente).

11. Los miembros de la FF.AA. y PNP están sometidos al Fuero Militar o Justicia Militar y al Código Penal Militar Policial, cuando cometan delito de función; de manera obligatoria, porque así lo instituye la observancia del debido proceso, establecido en los arts. $173 .^{\circ}$ y $139 .^{\circ}$, inc. 3) de la Carta Política.
12. El Estado escogió por otorgar protección legal al personal de la PNP cuando hagan uso reglamentario del uso de la fuerza; por lo que, solo alcanzarán ser investigados bajo comparecencia con restricciones y no en prisión preventiva; quedando prohibido dictar mandato de detención preliminar judicial y prisión preventiva establecido en el código adjetivo penal. De este modo, el Sistema de Defensa Jurídica del Estado, a través del procurador público especializado en la defensa legal del agente de la PNP se activa, brindando la asesoría y defensa legal gratuita al personal policial que afronta una investigación fiscal o un proceso penal o civil derivado del cumplimiento de la función policial.

13. El policía que hace uso de sus armas o medios de defensa, contraviniendo la Constitución Política del Perú y las normas del derecho Internacional Humanitario $(\mathrm{DIH})$ reconocidas por el Estado peruano, incurrirá en responsabilidad penal y no se le aplicarán los beneficios de la norma acotada.

14. El coronavirus, enfermedad considerada como pandemia por la Organización Mundial de Salud (OMS), está dejando miles de muertos e infectados en todo el mundo; y por el bien de los peruanos, el gobierno declaró el estado de emergencia nacional de salud. Lo que conlleva a consecuencias en la aplicación del uso de la fuerza coactiva por parte del Estado, a través de los policías y militares y, restricciones de confinamiento, órdenes de cerrar negocios no esenciales y limitar los viajes, distanciamiento social, constituyendo limitaciones a la libertad de manera excepcional y legal.

15. El Estado peruano en la lucha contra el coronavirus ha lanzado el programa Te Cuido Perú; una estrategia sanitaria más fina e inteligente que permitirá pasar de una cuarentena masiva a cuarentenas selectivas y quirúrgicas y reanudar la actividad económica.

\section{RECOMENDACIONES}

Para el control de conflictos sociales con el uso de la fuerza pública debe tenerse en cuenta el nivel de cooperación, resistencia o agresión que personifique el poblador al enfrentar la situación a controlar. Por otra parte, para solucionar diversas oposiciones al gobierno, se advierte que levantar las medidas prontamente podría propagar el contagio, pese a que también el cierre de los comercios y otras actividades cotidianas repercuten directamente en las inversiones que actualmente parecen retraerse o retirarse en la economía nacional.

Formular el protocolo o un plan para la reapertura gradual de las actividades en el país, en los diversos sectores, incluyendo las reglas para una buena higiene personal y la implementación 
de políticas por parte de los empleadores para garantizar el distanciamiento social, la aplicación de pruebas, el seguimiento de contactos a fin de lograr la cura para esta enfermedad; sin olvidar que debemos cambiar radicalmente los patrones de consumo correlacionados con enfermedades de emergencia ambiental.

Para el manejo de la salud pública, el Poder Ejecutivo debe abocarse a reformar estructuralmente el sector; de modo que los gobiernos regionales y locales pasen a desempeñar nuevos roles vinculados con la salubridad, mejorando la coordinación interinstitucional. De igual modo se recomienda construir las herramientas necesarias para garantizar que el presupuesto se gaste efectivamente en mejoras en las condiciones del personal médico o sanitario, el equipamiento y la infraestructura que hoy exhibe grietas por todos los flancos.

Existiendo mucha gente que vive en actividad día a día, que va a tener que elegir entre morirse de hambre o morir en encierro, debemos reflexionar sobre la necesidad de tener un Estado con políticas que pueda dar a toda la ciudadanía, seguridad, educación y salud; resolviendo el problema del desempleo y evitando que mueran más pobres, viejos sin recursos y olvidados.

\section{REFERENCIAS BIBLIOGRÁFICAS}

Bautista, T. (2012). Introducción al Derecho. Teorías sobre el ser del Derecho. Lima. Perú: Ediciones Jurídicas.

Bloom, B. S. (1956). Taxonomy of educational objectives. New York; Toronto. Estados Unidos. Recuperado de http://www.icomoscr.org/m/investigacion/\%5BMETODOS\%5DObjetivosTaxonomiaBloom.pdf

Caballero, V. (2020). Perú: la nueva normativa. NODAL Noticias de América Latina y el Caribe. Recuperado de https://www.nodal.am/2020/05/peru-la-nuevanormalidad-por-victor-caballero-martin/

Castro, A. (2014). Buen Gobierno y derechos Humanos. Nuevas perspectivas en el derecho público para fortalecerla legitimidaddemocráticadelaadministraciónpública en el Perú. Lima, Perú: Pontificia Universidad Católica del Perú. Recuperado http://cdn01.pucp.education/ idehpucp/wp-content/uploads/2017/06/28153702/ pub051buengobiernoddhh.pdf

Cuentas, E. (1997). El Abuso del Derecho. Recuperado de http://www.revistas.pucp.edu.pe/index.php/ derechopucp/article/download/6225/6262

Delgado, L. (2009). Tema 2. El enfoque de las políticas públicas. En: Documentación sobre gerencia pública, del Subgrupo A2, Cuerpo Técnico, especialidad de Gestión Administrativa, de la Administración de la Junta de Comunidades de Castilla-La Mancha. La
Mancha, España: Consejería de Administraciones Públicas. Escuela de Administración Regional.

El Comercio. (2011). De estas muertes, 153 fueron civiles y 38 policías y militares, 23 de los cuales fueron abatidos durante el violento paro en Bagua conocido como el "Baguazo". (28 de agosto de 2011), p.3.

El Comercio. (2020). Las fuerzas del orden resguardan el cumplimiento del estado de emergencia sanitaria. (23 de abril de 2020). El Comercio. p.3

Kant, I. (1983). Critica de la razón pura. Madrid, España: Biblioteca de traducciones españolas.

Luque, R. (2014). Conflictos sociales y uso de la fuerza. Blog de la Defensoría del Pueblo. Recuperado de https:// www.defensoria.gob.pe/blog/conflictos-socialesy-uso-de-la-fuerza-primero-la-vida/

Maiztegui, B. (2020). Ciudades contemplan impulsar el uso de bicicletas frente a la crisis del COVID-19. ArchDaily. Recuperado de https://www.archdaily.pe/pe/938611/ ciudades-contemplan-impulsar-el-uso-de-bicicletas-frente-a-la-crisis-del-covid-19

Ministerio de Desarrollo e Inclusión Social (2020 \#YoMeQuedoEnCasa [Aplicación móvil]. Google Play. https:// play.google.com/store/apps/details?id=peruentusmanos.gob.pe\&hl=es_CL

Oré, A. (2014). Manual Derecho Procesal Penal. Las medidas de coerción en el proceso penal. Lima, Perú: Editorial Reforma

Presidencia de la Republica. (2012). Decreto Legislativo n. ${ }^{\circ} 1186$ que regula el uso de la fuerza por parte de la Policía Nacional del Perú. Lima: Presidencia de la Republica.

Radbruch, G. (2005). Introducción a la Filosofía del Derecho México, Buenos Aires: Fondo de Cultura Económica.

Rosas, J. (2015) El derecho constitucional y procesal constitucional en sus conceptos claves: un enfoque doctrinario y jurisprudencial. Lima, Perú: Gaceta Jurídica.

Torré, A. (2003). Introducción al Derecho. Buenos Aires, Argentina: Perrot.

Tribunal Constitucional (2009). Demanda de inconstitucionalidad interpuesta por treinta y un Congresistas de la República, actuando como apoderado don Daniel Abugattás Majluf, contra la segunda parte del primer párrafo y el segundo párrafo del artículo $7^{\circ}$ de la Ley N. 0 29166, publicada en el diario oficial El Peruano el 20 de diciembre de 2007, mediante la cual se establece las reglas de empleo de la fuerza por parte del personal de las Fuerzas Armadas en el territorio nacional. Lima: Tribunal Constitucional.

\section{Fuentes de financiamiento}

Autofinanciado.

Conflictos de interés

No existe ningún conflicto de interés.

Correspondencia

Dirección: Av. Colectora edificio Luzmila Templo 205

Celular: 962696423

Email: uladislao.zevallos@udh.edu.pe 